\title{
Retroperitoneal Fibrosis: A Case Report of Five Patients and Short Review of the Literature
}

\author{
Karolina Feldman ${ }^{1 *}$, Judit Pulai ${ }^{1}$, Melinda Zsuzsanna Szabó ${ }^{2}$ and Emese Kiss ${ }^{2,3}$ \\ ${ }^{1}$ Department of Rheumatology, SzentGyörgy University Teaching Hospital of County Fejér, Hungary \\ ${ }^{2}$ Department of Clinical Immunology, National Institute of Rheumatology and Physiotherapy, Hungary \\ ${ }^{3}$ Department of Internal Medicine, Semmelweis University, Hungary
}

Submission: March 16, 2017; Published: April 18, 2017

*Corresponding author: Karolina Feldman, SzentGyörgy University Teaching Hospital of County Fejér, Hungary, Tel.: +36-22-535-500;

Email: feldman.karolina@gmail.com

Keywords: Retroperitoneal fibrosis; Periaortitis; IgG4-related disease

Abbreviations: RPF: Retroperitoneal Fibrosis; IgG4-RD: IgG4-Related Disease; IRF: Idiopathic Retroperitoneal Fibrosis; CP: Chronic Periaortitis; IAAs: Inflammatory Abdominal Aortic Aneurysms; PRF: Perianeurysmal Retroperitoneal Fibrosis; LDL: Low-Density Lipoprotein; ANA: Anti-Nuclear Antibody; Ati-TPO: Anti-Thyroid Peroxidase; Anti-TG: Anti-Thyroglobulin; ASMA: Anti-Smooth Muscle Antibodies; ANCA: Anti-Neutrophil-Cytoplasmic Antibodies; CRP: C-Reactive Protein; ESR: Erythrocyte Sedimentation Rate; CT: Computer Tomography; MRI: Magnetic Resonance Imaging; MMF: Mycophenolate Mofetil; AZA: Azathtioprine

\section{Introduction}

Retroperitoneal fibrosis (RPF) is a rare disease characterized by inflammation and deposition of fibrotic tissue around the aorta and iliac arteries often spreading in the retroperitoneal space to adjacent structures and thus leading to various complications, of which the most severe is ureter obstruction [1,2]. The majority (cca.2/3) of RF cases are considered to be primary/ idiopathic. Secondary causes of RF can be malignancies, drugs, medical interventions, trauma or infections [2]. About half of the idiopathic cases can be related to the newly discovered IgG4related disease (IgG4-RD) $[3,4]$.

IRF (idiopathic retroperitoneal fibrosis) is one of the three forms of chronic periaortitis (CP). The other two are the aneurysmal forms of CP: inflammatory abdominal aortic aneurysms (IAAs) with no involvement of periaortic structures and perianeurysmal retroperitoneal fibrosis (PRF) in which surrounding structures are also involved $[5,6]$.

The pathogenesis of IRF is still largely unclear. The most accepted theory suggests a local inflammatory response, the oxidized low-density lipoprotein (LDL) and ceroid in the atherosclerotic plaques are presented by macrophages to $\mathrm{T}$ and $\mathrm{B}$ lymphocytes triggering an inflammatory reaction in the adventitia [6]. However, these changes are also found approximately in half of the patients with ischemic heart disease and also in many elderly controls. Moreover, this theory cannot explain the generalized features of RF: the elevated inflammatory markers, positive auto antibodies (often antinuclear antibody, ANA) and concomitance of other autoimmune disease [7-10] and also cannot explain juvenile forms of IRF and IRF without atherosclerosis [2].

Lately, CP is thought to start as a primary aortitis which can trigger a fibro inflammatory process in the retroperitonium [2]. The finding, that histopathological features of CP and vasculitis are strikingly similar suggests that chronic periaortitiscan be a form of large vessel vasculitis [11,12]. Several studies also suggest the role of genetic factors in the pathogenesis of $\mathrm{CP}$, strongly associated with the presence of HLA-DRB1*03 [9].

The recently discovered IgG4 related disease is a clinically heterogeneous disease characterized by increased plasma IgG4 levels and tissue infiltration of IgG4-positive plasma cells, and may involve multiple organs. The most common locations are the pancreas, bile ducts, lymph nodes, lacrimal glands, kidneys and salivary glands [4]. The initial symptoms and laboratory findings are non-specific. Elevated serum IgG4 levels may indicate a more severe disease [13]. Inflammatory markers and ANA are positive in $30-40 \%$ of patients, with some less frequently detected auto antibodies including anti-thyroid antibodies [(anti-thyroid 
peroxidase (anti-TPO), anti-thyroglobulin (anti-TG)], antismooth muscle antibodies (ASMA), rheumatoid factor, and antineutrophil-cytoplasmic antibodies (ANCA) [2].

Diagnosis of RPF is difficult as the laboratory findings are non-specific: elevated C-reactive protein (CRP), erythrocyte sedimentation rate (ESR) and increased serum creatinine. Normocytic, normochrom anemia is also frequently present as a consequence of chronic inflammation. Leukocytosis, eosinophilia, proteinuria and hematuria, hypoalbuminaemia, hyper gamma globulinaemia may also be found but much more rarely [14,15]. Abdominal ultrasonography is often used as a screening test. RPF shows as a hypo- or anechoic well-demarcated but irregular mass [16]. Currently, the key to diagnosing RPF is computer tomography (CT) or magnetic resonance imaging (MRI). CT scans typically show a demarcated mass at the level of the L4-L5 vertebrae [17], while MRI usually shows the hypo intensity of the T1-weighted signal [18]. Besides the diagnostic process, imaging techniques can be used to assess progression or therapy success. Positron emission tomography with 18F-fluorodeoxyglucose (FDG-PET) and PET-CT can be helpful in making therapeutic decisions [19]. The final diagnosis should be based on the histopathological examination of biopsies $[2,16]$.

Management of RPF is mainly based on the inhibition of inflammation and fibrosis, usually by using prednisone or even methotrexate in combination in some cases. There are some promising results with mycophenolate mofetil (MMF), combination of prednisone and azathtioprine (AZA) or cyclophosphamide. Tamoxifen may provide alternative therapy. Rituximab in context of IgG4-RD, infliximab and tocilizumab are all promising [2].

\section{Case Reports}

Hereby we report our experiences with five patients admitted to the National Institute of Rheumatology and Physiotherapy, Department of Clinical Immunology, Adult- and Pediatric Rheumatology between 2010 and 2016 diagnosed with retroperitoneal fibrosis. Usually the first signs of RPF were pyelectasia, decreased GFR and/or symptoms of ureteral obstruction. RPF was diagnosed with CT and biopsy, in which no IgG4-positve case was found.

\section{Results}

The mean age of the patients was 59.2 years with male predominance (male: female ratio was 5:3). Our laboratory findings were elevated CRP, ESR, creatinine, and in one case proteinuria and ANA positivity.

We started $1-2 \mathrm{mg} / \mathrm{kg}$ corticosteroid and $0.75-1 \mathrm{~g} / \mathrm{m}^{2}$ cyclophosphamide as induction therapy. In case of the first patient the former therapy proved to be ineffective as the fibrosis progressed even to the mediastinum, so we switched to rituximab and later tocilizumab, which finally stopped the progression. In case of the second patient retroperitoneal fibrosis showed regression after the cyclophosphamide treatment, and later the orally administered mycophenolate mofetil proved to be effective leading to remission. During cyclophosphamide infusions adverse events were candida endophtalmitis and urosepsis, successfully treated with antifungal and antimicrobial therapy.

Treatment led to regression in two patients, in one case the progression stopped and two patients are currently receiving treatment and awaiting further assessment.

\section{Conclusion}

Retroperitoneal fibrosis is a rare disease with largely unknown pathogenesis usually causing non-specific symptoms and laboratory markers. In our cases corticosteroids and cyclophosphamide treatments proved to be effective first line therapy. As in case of most (if not all) autoimmune diseases, the ultimate goal of curing all patients seems only possible with individualized therapy due to the heterogeneous pathophysiology underlying the similar clinical conditions . But until then, a zillion of questions still need to be answered.

\section{References}

1. Brandt AS, Kamper L, Kukuk S, Haage P, Roth S (2011) Associated findings and complications of retroperitoneal fibrosis in 204 patients: results of a urological registry. J Urol 185(2): 526-531.

2. Runowska M, Majewski D, Puszczewicz M (2016) Retroperitoneal fibrosis-the state-of-the-art. Reumatologia 54(5): 256-263.

3. Khosroshahi A, Carruthers MN, Stone JH, Shinagare S, Sainani N, et al. (2013) Rethinking Ormond's disease: "idiopathic" retroperitoneal fibrosis in the era of IgG4-related disease. Medicine (Baltimore) 92(2): 82-91.

4. Zen Y, Onodera M, Inoue D, Kitao A, Matsui O, et al. (2009) Retroperitoneal fibrosis: a clinicopathologic study with respect to immunoglobulin G4. Am J Surg Pathol 33(12): 1833-1839.

5. Parums DV (1990) The spectrum of chronic periaortitis. Histopathology 16(5): 423-431.

6. Parums DV, Brown DL, Mitchinson MJ (1990) Serum antibodies to oxidized low-density lipoprotein and ceroid in chronic periaortitis. Arch Pathol Lab Med 114(4): 383-387.

7. Vaglio A, Manenti L, Allegri L, Ferrozzi F, Corradi D, et al. (2002) ANCA-positive periaortic vasculitis: does it fall within the spectrum of vasculitis? J Intern Med 251(3): 268-271.

8. Kermani TA, Crowson CS, Achenbach SJ, Luthra HS (2011) Idiopathic retroperitoneal fibrosis: a retrospective review of clinical presentation, treatment, and outcomes. Mayo Clin Proc 86(4): 297-303.

9. Martorana D, Vaglio A, Greco P, Zanetti A, Moroni G, et al. (2006) Chronic periaortitis and HLA-DRB1*03: another clue to an autoimmune origin. Arthritis Rheum 55(1): 126-130.

10. Palmisano A, Urban ML, Corradi D, Cobelli R, Alberici F, Maritati F, et al. (2015) Chronic periaortitis with thoracic aorta and epiaortic artery involvement: a systemic large vessel vasculitis? Rheumatology (Oxford) 54(11): 2004-2009.

11. Salvarani C, Pipitone N, Versari A, Vaglio A, Serafini D, et al. (2005) Positron emission tomography (PET): evaluation of chronic periaortitis. Arthritis Rheum 53(2): 298-303. 
12. Vaglio A, Pipitone N, Salvarani C (2011) Chronic periaortitis: a largevessel vasculitis? Curr Opin Rheumatol 23(1): 1-6.

13. Pelkmans LG, Hendriksz TR, Westenend PJ, Vermeer HJ, van Bommel EF (2017) Elevated serum IgG4 levels in diagnosis and treatment response in patients with idiopathic retroperitoneal fibrosis. Clin Rheumatol 36(4): 903-912.

14. Vaglio A, Salvarani C, Buzio C (2006) Retroperitoneal fibrosis. Lancet 367(9506): 241-251.

15. van Bommel EF, Jansen I, Hendriksz TR, Aarnoudse AL (2009) Idiopathic retroperitoneal fibrosis: prospective evaluation of incidence and clinicoradiologic presentation. Medicine (Baltimore) 88(4): 193201

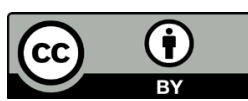

his work is licensed under Creative Commons Attribution 4.0 License DOI: 10.19080/JOJUN.2017.02.555593
16. Cronin CG, Lohan DG, Blake MA, Roche C, McCarthy P, et al. (2008) Retroperitoneal fibrosis: a review of clinical features and imaging findings. AJR Am J Roentgenol 191(2): 423-431.

17. Amis ES (1991) Retroperitoneal fibrosis. AJR Am J Roentgenol 157(2): 321-329.

18. Vivas I, Nicolás AI, Velázquez P, Elduayen B, Fernández-Villa T, et al. (2000) Retroperitoneal fibrosis: typical and atypical manifestations. Br J Radiol 73(866): 214-222.

19. Caiafa RO, Vinuesa AS, Izquierdo RS, Brufau BP, Ayuso Colella JR, et al. (2013) Retroperitoneal fibrosis: role of imaging in diagnosis and follow-up. Radiographics 33(2): 535-552.

\section{Your next submission with Juniper Publishers will reach you the below assets}

- Quality Editorial service

- Swift Peer Review

- Reprints availability

- E-prints Service

- Manuscript Podcast for convenient understanding

- Global attainment for your research

- Manuscript accessibility in different formats

( Pdf, E-pub, Full Text, Audio)

- Unceasing customer service

Track the below URL for one-step submission https://juniperpublishers.com/online-submission.php 